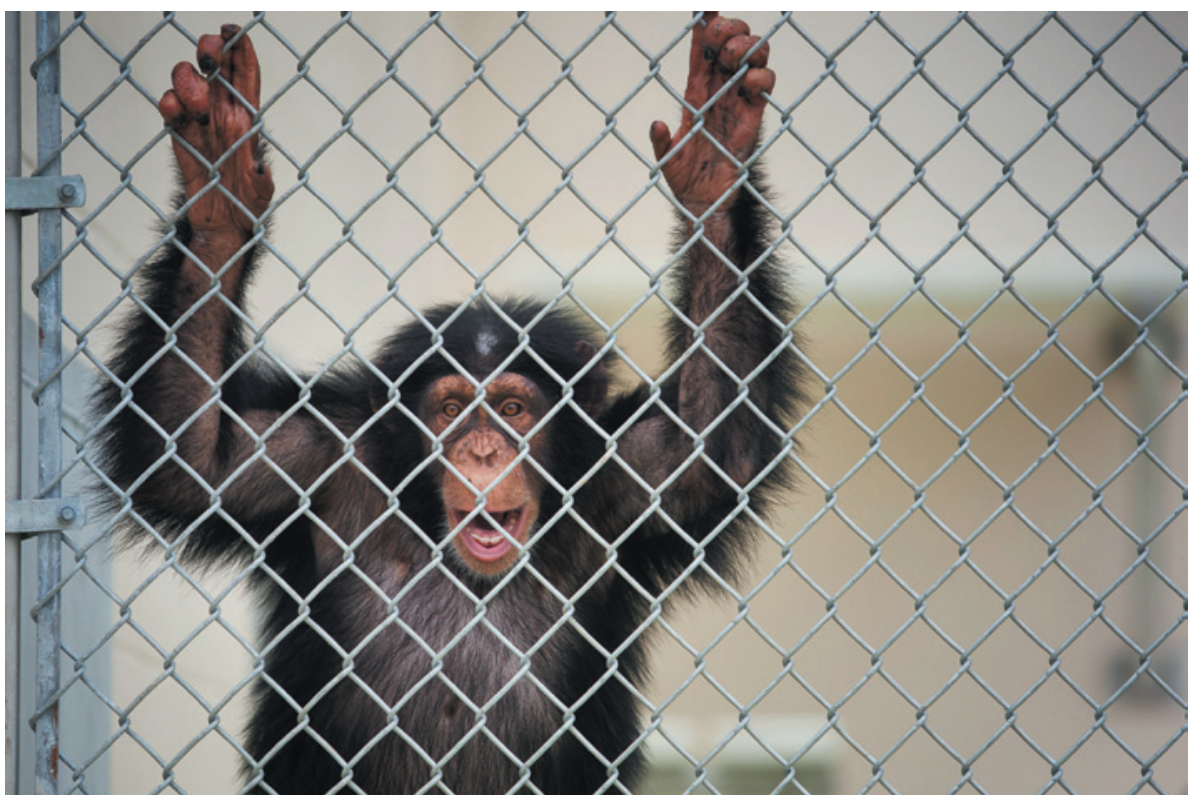

Tightened standards could pose a barrier to all but a few studies making use of research chimps.

ANIMAL EXPERIMENTATION

\title{
Chimp research under scrutiny
}

\section{US-government-funded studies to be evaluated under stricter criteria.}

\section{BY MEREDITH WADMAN}

A landmark report published by the Institute of Medicine (IOM) last week has triggered the US government to reconsider what, if any, chimpanzee research should receive funding. It has also left Christopher Walker pondering the implications for an enterprise close to his heart - developing a preventive vaccine against the hepatitis $\mathrm{C}$ virus $(\mathrm{HCV})$.

Walker, director of the Nationwide Children's Hospital's Center for Vaccines and Immunity in Columbus, Ohio, found himself agreeing with many of the recommendations in the report, which was released on 15 December. They include strict criteria for assessing when chimps can be used in research projects (see 'Raising the bar for chimp research'), and the establishment of an expert committee to judge proposed studies on a case-by-case basis.

Walker even agreed that no chimp experiment aimed at developing therapies for the 170 million people worldwide infected with HCV would meet those criteria. For example, although the chimp is the only other animal susceptible to HCV infection, new in vitro culture systems and small-animal models containing human cells offer alternatives.

What gave Walker pause was an issue that split the otherwise-unanimous IOM authors. Only half felt that chimpanzees may be necessary to identify HCV vaccine candidates for use in humans. The split makes it hard to predict whether government-funded $\mathrm{HCV}$ vaccine researchers will still be approved to work with chimps. "If you have an idea for an entirely new approach to vaccination, but can't get proof of that principle in animals, my fear is that it will never move ahead into human trials," says Walker, who is studying protective immunity to HCV in chimps.

Although the IOM report leaves the door partly open for $\mathrm{HCV}$ vaccine research, in other disease areas it is less equivocal. Jeffrey Kahn, the committee chair and deputy director of policy and administration at Johns Hopkins University's Berman Institute of Bioethics in Baltimore, Maryland, notes that only one other active research area meets the IOM standards: existing studies in which chimps are used to produce monoclonal antibodies and to test their safety. "No other current biomedical research areas were seen as meeting the committee's criteria," Kahn says.

During a media briefing after the report's release, Francis Collins, the director of the National Institutes of Health (NIH) in Bethesda, Maryland, which supports 612 chimps and oversees most of the government's chimp research, said that 37 agency-funded chimp studies would be evaluated under the report's criteria. Those that do not pass muster will be phased out; no new studies involving experimentation on chimps will be funded unless the criteria are met.

\section{DIVIDED OPINION}

The committee's split over the use of chimps to identify promising $\mathrm{HCV}$ vaccine candidates reveals a fault line within the biomedical community. In a letter sent to the committee on 25 September, 100 scientists, including several Nobel laureates, argued that, without access to the chimp, there will be a "substantial delay" in creating an effective vaccine, and that there is no guarantee that promising-looking alternatives, such as mouse models, will prove to be effective.

Yet the report's conclusions reflect the tenor of the times, as well as the progress of alternatives to animal research. Public opposition to the use of chimps in research has grown steadily. This is reflected in proposed legislation on Capitol Hill that would ban invasive and comparative-genomic chimp research, and in a petition from animal-welfare groups being considered by the US Fish and Wildlife Service to declare research chimps as endangered, which would effectively end any chimp research not aimed at conservation.

The IOM report was requested by the NIH after high-profile politicians and activists protested against the agency's plan to move 186 semi-retired chimps back into active research (Nature 467, 507-508; 2010). The committee wrote that its deliberations, although formally considering only scientific necessity, were "suffused with an awareness

\section{RAISING THE BAR FOR CHIMP RESEARCH}

Experiments will need to comply with these criteria to win funding from the National Institutes of Health.

\section{Biomedical studies}

No other suitable model is available The study cannot be performed ethically in humans

Important advances would be significantly slowed or prevented if the study was not done Chimps must be housed in appropriate physical and social environments or in natural habitats

\section{Comparative-genomics and behavioural studies}

The study provides otherwise unattainable insight

The study is performed on acquiescent animals using minimally invasive techniques in a manner that minimizes pain and distress Chimps must be housed in appropriate physical and social environments or in natural habitats 
of the moral cost of such research".

Researchers are divided over the number of experiments that stand to be affected. Collins guesses that "something like 50\%" of the $37 \mathrm{NIH}$-funded experiments would be curtailed, but the directors of the three NIHsupported research centres that conduct invasive experiments say that they carried out only seven such experiments with NIH funded chimps this year.

The paucity of invasive experiments, they say, shows that chimps are already being used highly selectively. "There are some assumptions, it seems, that the IOM criteria were not being applied already. And I think that's incorrect," says Thomas Rowell, director of the New Iberia Research Center in Louisiana, the largest US chimp research centre.

Two of four projects using chimps at the Michale E. Keeling Center for Comparative Medicine and Research near Bastrop, Texas, this year involved testing treatments on chimps chronically infected with hepatitis C. A third studied hepatitis-C infectivity and the fourth involved HIV/ AIDS. All four are either complete or near completion, so are unlikely to be affected by the new recommendations.

John VandeBerg, director of the Southwest National Primate Research Center in San Antonio, Texas, says that there are two $\mathrm{NIH}$-funded studies under way there. "It is my judgement that both of these studies would qualify for continuation" under the IOM criteria, he says.

But animal-welfare activists are pleased that the committee came down resoundingly on the side of less is better. Even in the case of a preventive HCV vaccine, says Kathleen Conlee, senior director for animal-research issues at the Humane Society of the United States in Washington DC, "it didn't say, 'We absolutely need chimps for this', but rather, 'We couldn't decide"'.

Supporters of chimp research take heart from a separate IOM observation that a new or re-emergent disease could require the use of chimps in the future. "The IOM report is the first authoritative document to acknowledge the very real possibility that new and emerging threats to human health may require access to chimps," says Christian Abee, director of the Keeling Center. "A plan will have to be developed to ensure that chimps are available in the future."

When asked whether the new report will require a reassessment of the chimpbreeding ban that the NIH put in place in 1995, Collins says that he does not have an analysis showing how many chimps should "be kept on hand should the need arise from some sort of new pandemic for their use". But, he says, "with more than 600 chimps already available and owned by the NIH, it seems as though we have a pretty substantial population to work with".

\section{Rules on integrity signal tighter stance}

\section{BY EUGENIE SAMUEL REICH}

$\mathrm{W}$ hen Kathleen Sebelius, secretary of the US Department of Health and Human Services, overruled the Food and Drug Administration (FDA) on 7 December and denied over-the-counter access to the Plan B One-Step 'morning-after' pill for girls aged under 17, advocates for scientific integrity in government were outraged. Although the FDA's decision to allow access had been based on an in-depth scientific review, Sebelius - who is not a scientist by training claimed that the data did not support the view that young girls would be able to use the drug safely. "The key problem is she re-reviewed the science," says Francesca Grifo of the Union of Concerned Scientists in Washington DC.

It is no small irony that a row over political interference in scientific decision-making should erupt just as President Barack Obama’s initiative to shield government scientists from such pressures comes to fruition. Agencies and departments across the US government have been working to submit final drafts of scientific-integrity policies, many of which make some reference to disallowing politically motivated alteration of data.

The policies were due to be submitted to the government's Office of Science and Technology Policy (OSTP), where its director John Holdren is overseeing the process, by 17 December. Last week, Nature conducted its own survey of the effort by contacting agencies directly. Of the 11 departments and agencies that have confirmed to Nature that they are drafting new policies, six now have public policies that make some reference to forbidding politically motivated alteration of data. A seventh, the Department of Justice, has told Nature that a working draft does so.

But three agencies - the Department of Health and Human Services, the Department of Energy and the Department of Defense have not made their policies public or answered Nature's questions about them. A fourth agency - the National Institute of Standards and Technology (NIST) - has no public policy but has told Nature that a working draft does not explicitly ban political alteration of data. Henry Wixon, the chief counsel for NIST, says that this has not traditionally been an issue at the agency, but adds that he may consider amending the NIST draft policy. Similar shifts have taken place at NASA and the National Science Foundation, both of which included language banning political interference in the latest versions of their integrity policies, released in the past week. Earlier drafts did not include such language.

The stakes are highest at regulatory agencies where science directly informs policy. Among these, the Environmental Protection Agency has moved forward with asserting that the work of its scientists and engineers should be free from political influence. However, critics have complained that the agency's draft policy could be clearer about the fact that the requirement applies to agency political appointees, not just to scientists employed by it. Another regulatory agency, the energy department, received a letter on 15 December from the Project on Government Oversight, a watchdog group based in Washington DC, calling for its policy to include an independent oversight mechanism for breaches of research ethics.

Yet some question whether the integrity policies go far enough. It is far from clear, for example, whether such a policy at the Department of Health and Human Services would have prevented the furore over Plan B.

Nick Steneck, a research ethicist at the University of Michigan in Ann Arbor, says that the OSTP should offer stronger leadership to make it clear that integrity policies must address political interference. "Issuing a simple document is not sufficient," he says. = SEE EDITORIAL P.413

\section{CORRECTIONS}

The graph of a hypothetical stock portfolio in the News story 'Blockbuster drug bows out' (Nature 480, 16-17; 2011) omitted the effects of dividends and stock splits; instead of losing $39 \%$, it should have risen by $82 \%$. Similarly, US $\$ 100$ worth of Pfizer stock in 1986 would have grown to $\$ 2,139$ by 1999 and shrunk to $\$ 1,629$ by the end of 2010 .

The News Feature 'Master of illusion' (Nature 480, 168-170; 2011) wrongly attributed the idea "if there's something you can be certain of in this world, it's that your hand is your hand" to Descartes instead of G. E. Moore. 